\title{
SECURITIZAÇÃO DO CRIME ORGANIZADO TRANSNACIONAL NA AMÉRICA DO SUL E O SURGIMENTO DE NOVAS AMEAÇAS
}

\author{
THE SECURITIZATION OF TRANSNATIONAL ORGANIZED CRIME IN SOUTH AMERICA \\ AND THE EMERGENCE OF NEW THREATS
}

Alessandro Luiz Chichoski ${ }^{1}$

\begin{abstract}
Resumo
Este artigo aborda a securitização do Crime Organizado Transnacional na América do Sul diante do surgimento de novas ameaças, especialmente pelo tráfico de drogas, de pessoas, conflitos, crimes, violência e instabilidade política nos países fronteiriços. O objetivo do estudo é analisar como se desenvolvem as estratégias de securitização diante do surgimento de novas ameaças que evoluem no contexto do Crime Organizado Internacional (COT) na América do Sul. Trata-se de uma pesquisa com abordagem qualitativa que se caracteriza como uma revisão bibliográfica de fontes teóricas relacionadas ao assunto. Os principais assuntos debatidos são permeados pela compreensão das estratégias, teorias de relações internacionais e as medidas adotadas em diferentes espaços da América do Sul na busca de compreender e controlar as ameaças que colocam em risco a autonomia e a segurança internacional no continente americano.
\end{abstract}

Palavras-chave: Novas ameaças; Segurança Internacional; Securitização; Crime Organizado Transnacional.

\begin{abstract}
This article deals with the securitization of Transnational Organized Crime in South America in the face of the emergence of new threats, especially drug trafficking, people, conflicts, crimes, violence and political instability in the border countries. The objective of the study is to analyze how the strategies of securitization are developed in the face of the emergence of new threats that evolve in the context of International Organized Crime (TOC) in South America. It is a qualitative approach that is characterized as a review of theoretical sources related to the subject. The main issues discussed are permeated by an understanding of the strategies, theories of international relations and the measures adopted in different spaces of South America in the search to understand and contend the threats that endanger autonomy and international security in the American continent.
\end{abstract}

Keywords: New threats; International Security; Securitization; Transnational Organized Crime.

\section{INTRODUÇÃO}

A securitização em relação ao Crime Organizado Transnacional (COT) vem sendo objeto de estudo nas últimas décadas, especialmente considerando que se devem desenvolver ações

1 Mestrando no Programa de Pós-Graduação em Integração Contemporânea da América Latina. Especialista em Relações Internacionais Contemporâneas pela Universidade Federal da Integração LatinoAmericana (UNILA). Email: chichoski.adv@gmail.com. 
concretas de prevenção e contenção em espaços considerados vulneráveis. Neste aspecto, a América Latina se apresenta como um dos espaços que mais necessita de intervenção, pois possui grandes extensões de fronteiras terrestres que ameaçam a segurança internacional.

Aspectos históricos das políticas internacionais são determinantes na identificação e no combate ao Crime Organizado Transnacional (COT). O fim da Guerra Fria e consequentemente o surgimento da hegemonia unipolar dos Estados Unidos, colocou em evidência as novas ameaças representadas pelos conflitos, crimes e violência estabelecidos nos países periféricos, especialmente, os países latino americanos.

A América Latina configura-se como um espaço marcado pela violência, pela produção de drogas ilícitas e narcotráfico e pela instabilidade política antagônica aos interesses norte americano, entre outros problemas gerados pela interdependência entre os países pobres e ricos do continente americano. Nota-se, que os conflitos sul-americanos, mesmo não resultando de força externa, a exemplo do COT, conforme aponta Ferreira (2017), se constitui como ameaça difusa à paz que afeta sociedades diversas, estejam elas em conflito ou pós-conflito, sejam democráticas ou estabilizadas ${ }^{2}$.

O COT desenvolve características diferentes daquelas apresentadas no conflito tradicional, tendo como benefícios a facilitação tecnológica e econômica desencadeada pela globalização. Nota-se que investidas políticas dos EUA nortearam a região para possíveis agendas securitárias e, consequentemente, atuou na forma de combate a tais ameaças. $\mathrm{Na}$ América do Sul ocorre um pensamento alternativo para os crimes transnacionais, principalmente para aqueles ligados ao narcotráfico.

Diante disso, este artigo tem como objetivo analisar como se desenvolvem as estratégias de securitização diante do surgimento de novas ameaças que evoluem no contexto do Crime Organizado Internacional (COT) na América do Sul. Trata-se de uma análise de teorias e conceitos que permeiam os estudos epistemológicos que constituem como base do conhecimento desenvolvido a respeito do COT até o momento.

\section{MEDIDAS DE COMBATE AO CRIME ORGANIZADO TRANSNACIONAL (COT) NA AMÉRICA LATINA}

\footnotetext{
${ }^{2}$ Conflito é sinônimo de luta, guerra, combate, batalha, contenda, hostilidade, confronto. O pós-conflito é a oportunidade de coordenar as consequências do conflito quando se restabelece a paz. Nações Democráticas são aquelas cujo sistema político permite que os cidadãos elejam os seus dirigentes por meio de eleições periódicas e as Nações Estabilizadas correspondem àquelas que mantêm o poder centrado no Estado e determina regimes ditatoriais.
} 
A compreensão de como os Estados e Nações articulam o combate ao Crime Organizado Internacional parte do conhecimento relacionado às mudanças que ocorrem na organização hierárquica que articula a organização econômica e abre espaço para a atuação de novos investidores, pois existe uma influência da transnacionalização do crime organizado que incide sobre a segurança, a política e a humanização nos planos internos, regionais e internacionais. Por isso, estabelecem-se planos compartilhados que visam a manutenção da segurança, a criação de comunidades de cooperação internacional que combatem as organizações criminosas.

Neste contexto, foi criado no Continente Latino Americano um sistema de cooperação que culminou com o surgimento da UNASUL em 2008 representa uma concepção pautada nos seguintes objetivos:

"[...] Artigo 2 - A União de Nações Sul-americanas tem como objetivo construir,
de maneira participativa e consensuada, um espaço de integração e união no
âmbito cultural, social, econômico e político entre seus povos, priorizando o
diálogo político, as políticas sociais, a educação, a energia, a infra-estrutura, o
financiamento e o meio ambiente, entre outros, com vistas a eliminar a
desigualdade socioeconômica, alcançar a inclusão social e a participação cidadã,
fortalecer a democracia e reduzir as assimetrias no marco do fortalecimento da
soberania e independência dos Estados.

Artigo 3 - A União de Nações Sul-americanas tem como objetivos específicos: (...) q) a coordenação entre os organismos especializados dos Estados Membros, levando em conta as normas internacionais, para fortalecer a luta contra o terrorismo, a corrupção, o problema mundial das drogas, o tráfico de pessoas, o tráfico de armas pequenas e leves, o crime organizado transnacional e outras ameaças, assim como para promover o desarmamento, a não proliferação de armas nucleares e de destruição em massa e a deminagem" (UNASUL, 2008, p. 2, grifos meus).

Também em 2008 foi criado o Conselho de Defesa Sul-Americano (CDS), que dentro da UNASUL tem caráter de instância consultiva, de cooperação e coordenação em matéria de defesa, tendo como premissa a consolidação da América do Sul como zona de paz, visando o desenvolvimento integral dos povos. O CDS conta com o Centro de Estudos Estratégicos de Defesa (CEED), que deveria pautar seus estudos nas definições de segurança e defesa na América do Sul. Assim, sua função era identificar as questões relacionadas à defesa e estabelecer a área de atuação do CDS, para identificar os elementos de segurança e os que devem ser tratados em outro âmbito (LYRA, 2014).

O órgão apresenta que a América do Sul oferece um conjunto de fenômenos de criminalidade organizada e indicam novas ameaças representadas pelo tráfico de armas, tráfico de pessoas, tráfico de drogas, contrabando, descaminho e evasão de divisas, entre outros crimes.

A criminalidade transnacional registra uma diversidade constante de seus produtos e métodos de ação. As novas ameaças, derivam de outras diversas formas de crimes transfronteiriços e, consequentemente, no aumento da criminalidade e da violência. A ocorrência de tais crimes exigem ações eficazes no âmbito da segurança pública, exigindo mecanismos de cooperação específicos previstos pelos objetivos da UNASUL. 
Neste sentido em 2011 foi criado o Conselho Sul-Americano em Matéria de Segurança Cidadã, Justiça e Coordenação de Ações contra a Delinquência Organizada Transnacional (CSSCJDOT), com o objetivo de funcionar como uma "instância de consulta, coordenação e cooperação" entre os países sul-americanos em assuntos relacionados à segurança e justiça, além das ações contra o crime transnacional organizado (FRAMENTO, 2017).

A securitização relacionada com o COT na América do Sul, vem sendo motivo de preocupação dos Estados Unidos desde a década de 1990 devido ao combate ao narcotráfico. Essa é uma tendência direcionada à política externa norte-americana relacionada à "guerra as drogas" (FERREIRA, 2017).

Atividades como o tráfico de drogas, de produtos falsificados, de pessoas, de armas ilegais, geram ganhos anuais exorbitantes, segundo a United Nations Office on Drugs and Crime (UNODC), o COT nas suas mais diversas modalidades gera uma média de US\$ 650 bilhões anuais, ou 1,5\% do Produto Interno Bruto (PIB) mundial. Deste total, 92\% dos fundos são lavados e $20 \%$ do montante estão ligados ao tráfico de drogas (UNODC, 2012).

De acordo com Ferreira (2017), há poucas estatísticas que demonstram os impactos que o crime organizado gera, especialmente, como elemento que destrói a paz em todos os níveis sociais. As políticas direcionadas ao combate à criminalidade contribuem para levantar questões como: quais as influências que o combate às drogas mobilizam para incidir sobre o cenário de securitização, tanto nas políticas internas quanto externas dos países sul americanos?

Este questionamento decorre da constatação de que as intervenções e cooperações dos Estados Unidos com países da América Latina, como a penetração norte-americana para a implementação do Plano Colômbia, isto contribuiu para fomentar o exército colombiano e para que surgissem grupos paramilitares como as Autodefesas Unidas de Colômbia (AUC) a fim de militarizar o combate ao narcotráfico e a guerrilha, esta inserção americana visava promover o combate às Forças Armadas Revolucionárias da Colômbia (FARC), pois a guerrilha ganhou território e protege o cultivo da coca, isto contribui para que surjam inseguranças internas e internacionais na América do Sul (FREITAS, 2016).

Assim, todo este contexto envolvendo Colômbia e Estados Unidos, criou um cenário negativo na região, principalmente situações envolvendo países como Bolívia, Brasil e Argentina e também conflitos relacionado as relações da Colômbia com Equador e principalmente a Venezuela. A nação colombiana esteve envolvida em vários problemas como questões de refugiados, violação de soberania, problemas ambientais no âmbito interno do Estado (MEDEIROS, 2018).

O interesse dos Estados Unidos pelo hemisfério sul deve-se ao fato de que países como México e outros países da América Central servem de escoamento de drogas para o continente 
norte-americano, isto gerou preocupações com novas ameaças na segurança internacional. De acordo com Lyra (2014), os principais temas destacados são: o crime organizado, crimes transnacionais, disputas fronteiriças, insurreições armadas e guerrilhas, pois estes desestabilizam a política e levam governos a criar estratégias de combate ao tráfico de drogas, armas, pessoas, terrorismo, crime organizado, corrupção e lavagem de dinheiro.

De acordo com Freitas (2016), a preocupação com o crime organizado intensificou-se após a globalização econômica, onde antes as organizações criminosas limitavam-se ao modo de agir da máfia italiana, passou-se por um processo de evolução pautado na agilidade das comunicações e no uso da internet. Entretanto, segundo Almeida (2017), no mundo globalizado, os Estados e Nações precisam limitar suas ações respeitando os interesses e a autonomia dos outros países, ao mesmo tempo, o crime organizado não encontra barreiras para obter lucro através de atividades ilícitas.

Neste sentido, criminosos vivem numa sociedade em rede, com avanços tecnológicos, e por não se apegarem a regras nem obstáculos, realizam práticas que nem são previstas como crimes, pois se utilizam de uma dinâmica que se vale de muitas fronteiras, o que permite operar em países que apresentam práticas consideradas como crimes e que em outro país esta mesma prática não se configura como crime.

A criminalidade de hoje não tem fronteiras. Esta é a grande questão e o grande desafio que se põe ao Estado. Nenhum estado sozinho, nenhum Procurador sozinho, nenhuma polícia sozinha está em condições de investiga o que for. A dispersão da acção criminosa (no tempo e lugar) ultrapassando, muitas vezes, as fronteiras exige como resposta a cooperação judiciaria entre os Estados. (MOTA, José Luis Lopes da Mota, Vice-Presidente da Eurjust, seminário da Eurojust, Lisboa, 20-04-2006, in DAVIN, João, ob.cit., p. 07. Apud PEREIRA 2011).

O CDS, por meio do CEED, elenca várias recomendações para o combate do problema do narcotráfico e outros crimes transnacionais: 1) a necessidade de cooperação efetiva e sistemática para produzir uma resposta contundente ao problema, instituindo outro órgão (distinto do órgão de defesa), ou a reformulação do Conselho Sul-Americano de Luta contra o Narcotráfico, para tratar questões de cooperação e coordenação em matéria de segurança pública ou interior; 2) a partir desse órgão de segurança pública a ser criado ou da reformulação do órgão já existente, estabelecer uma Convenção Sul-Americana de luta contra o crime transnacional, bem como articular e coordenar políticas públicas para o enfrentamento do problema; 3) estabelecer estratégias de cooperação regional e apresentar um relatório regional sobre o crime organizado e transfronteiriço; e 4) articular a sociedade civil, os níveis municipais e comunitários no enfrentamento aos crimes transnacionais (CEED, 2012), demonstrando assim, a intensão em uma (des)securitização do combate as drogas.

Para Ferreira (2017), não há como negar que o COT se apresenta de forma generalizada nos países sul-americanos, e se aproveita da ineficiência da segurança pública, assim suas ações 
são pautadas no mercado global e, atualmente, aproveita-se do liberalismo político para desenvolver uma motivação econômica e se associar ao contrabando, ao mercado ilegal, ao narcotráfico, ao roubo, ao tráfico de pessoas, de armas e de órgãos.

\section{O CONCEITO DE SEGURANÇA, AMEAÇAS E SECURITIZAÇÃO DO CRIME ORGANIZADO TRANSNACIONAL}

Percebe-se que com o início da hegemonia unipolar americana que os estudos relacionados à segurança internacional passam por uma transformação por conta das modificações ocorridas no cenário externo mundial, nota-se que os conceitos relacionados à segurança internacional estavam atrelados basicamente a estudos voltados ao Estado como ator principal e os aspectos militares e estratégicos dentro da segurança. Entretanto, com o fim da Guerra Fria, houve redistribuição de poderes entre os atores deste sistema ampliando o escopo, e surgindo preocupações e necessidades de debates na agenda de segurança voltada para questões econômicas, sociais e também ambientais.

Para Buzan e Hansen (2012), dentre os conceitos de segurança abordados dentro dos Estudos de Segurança Internacional destacam-se o Construtivismo Convencional que tem o Estado como objeto de referência, atua principalmente no setor militar tendo sua formação epistemológica baseada no positivismo, já os Estudos Críticos de Segurança onde o indivíduo é o objeto de referência e atua em todos os setores baseia-se na Teoria Critica. Os Estudos Estratégicos onde o Estado é seu objeto principal atuando no setor militar (uso da força), tendo uma visão política voltada para segurança através da teoria Realista e sua epistemologia é positivista.

Em termos de estratégia, o positivismo relaciona os atores e as estruturas, o que torna relevantes os paradigmas e a crise da modernidade iluminista. Da mesma forma, a teoria realista é considerada estrategicamente incapaz de lidar com os fenômenos da interdependência e da transnacionalização, pois não pode conviver com o pós-positivismo e com o florescimento de instituições internacionais por ser um conceito de poder e racionalidade. Assim, em momentos de crise e de transformação é necessário promover estratégias que permitam historicizar e construir conceitos sociais críticos e construtivistas, pois isso permite desenvolver uma nova perspectiva de emancipação político-econômica (FERREIRA e FRAMENTO, 2017).

Buzan e Hansen (2012) consideram que a Escola de Copenhague apresenta-se como objeto de referência centralizando as suas perspectivas na coletividade e no meio ambiente, assim, as relações internacionais desenvolvem-se em todos os setores, tanto no âmbito externo como no interno, com uma visão política neutra e sua epistemologia baseada na análise do ato da fala. 
Portanto, faz-se necessário conceituar segurança em um sentido global que se expande ao nível de confronto a qualquer ameaça, qualquer perigo, nesse processo de transformação contínua e gradual que a forte e antiga identificação militar tem mitigado e se faz presente de forma metafórica, como guerras e desafios que afetam a soberania e a defesa (SAINT-PIERRE, 2007).

Normalmente os estudos da segurança internacional têm como objeto de referência a segurança dos Estados (população, território, fronteiras, recursos, etc), e nesse viés, o termo segurança equivale ao conceito de Estado em sua territorialidade. Desta forma, assume uma nova dimensão, desencadeando novas ameaças que não faziam parte das agendas de segurança, mas que no âmbito militar preocupa-se basicamente com a polarização capitalismo $x$ comunismo (FERREIRA, 2017).

Para Cepik (2010) a definição de segurança está relacionada como meio de proteção coletiva da sociedade contra ameaças pujantes a sua sobrevivência e sua autonomia, assim assume um papel relativo neste contexto. No entanto, de acordo com Ferreira (2017) segurança é a ausência do mal da insegurança, portanto, é medida a partir da ausência de ameaças e valores adquiridos, assim a violência direta pressupõe a existência clara de um executor que não impede indivíduos ou sociedade de alcançar algo (segurança), e também busca causar danos ou destruição aos mesmos.

A Escola de Copenhague discute o processo de securitização, projetando-o através de discursos, que são realizados por um ator que invoca a questão da segurança, com o intuito de trazer à tona uma preocupação referendada pela sua amplitude. Para que seja eficiente, são necessários três elementos que ameaçam um objeto referencial colocando em risco sua existência. É necessário adotar medidas excepcionais para sua proteção, desde que sejam justificadas e legítimas, a fim de quebrar procedimentos democráticos. As três características ajudam a elevar a questão do âmbito da baixa política, que segue as regras e os processos usuais da democracia, para a alta política, que se caracteriza pela urgência, prioridade e ação de vida ou morte (BUZAN et al., 1998, p. 21-26)

Assim, questões ligadas à economia e política tornam as cooperações mais difíceis, além disso, existem outras questões advindas do campo da segurança interna e da segurança internacional que são determinantes para a ocorrência de crimes transnacionais e o COT, o que exige medidas de securitização.

No sentido lato da segurança, deixando de lado somente questões militares e refletindo sobre o cotidiano e os problemas sociais, relações interpessoais (Estado $X$ crime), pois é importante ter a noção que o conceito será amplo e suas derivações poderão ser aplicadas no todo, portanto, o estudo que se desenvolve busca a solução para os problemas cotidianos e ameaças internas, que devem ser atacadas pelas estratégias de segurança. 
Se, contudo, queremos agregar algo de novo aos debates em curso sobre "segurança" (nos estudos estratégicos) e interesse nacional, devemos começar com aqueles debates, assumindo aquela problemática, para que possamos chegar às dinâmicas específicas daquele campo e mostrar como esses antigos elementos operam em novas maneiras e novos lugares (SAINT-PIERRE, 2007,p.62).

Deve-se considerar que as mesmas estratégias que são usadas no campo da defesa da soberania, no âmbito da segurança internacional, podem e devem ser empregados no campo da segurança doméstica, segurança interna, segurança social, ou seja, deve-se decifrar e empregar certos códigos para a aplicabilidade da mesma forma que é feita no campo da supracitada defesa.

$\mathrm{Na}$ sociedade internacional, por exemplo, um número de códigos, regras e entendimentos foi estabelecido de modo a tornar as relações internacionais uma realidade social intersubjetivamente definida, que possui suas próprias leis e questões específicas. A segurança nacional é, de maneira semelhante, social no sentido de ser intersubjetivamente constituída num campo específico, e não deve ser medida contra algum parâmetro real ou verdadeiro de "segurança" derivado da sociedade doméstica contemporânea (SAINT-PIERRE, 2007, p.65).

De acordo com Clausewitz (apud FERREIRA, 1994), a guerra é a continuação da política por outros meios. De tal afirmação, podem decorrer ensinamentos pertinentes, pois o objetivo da aplicação da segurança no seu sentido latu, pode acontecer com o emprego de atividades de persuasão ou diplomacia, e fazer com que oponentes ameaçadores sintam-se constrangidos, ou que compreendam que o poder do inimigo é maior e, portanto, ele deve executar a sua vontade.

Neste sentido, de acordo com Pereira (2011), as ações de cooperação devem ser construídas a partir de estratégias que possam danificar as bases dos ilícitos transnacionais, explorados pelo COT, focalizando controles de caráter econômicos para este mercado, principalmente na demanda e no consumo. Buzan e Waever (1998) também são enfáticos em dizer que a securitização é tomada por aqueles que percebem o discurso, e essas medidas são tomadas de forma coletivas e construídas dentro da sociedade, para tanto se faz necessário a ameaça ser vista como implicações de medidas urgentes e especiais, tendo uma relação com a segurança, sendo aceita como pertinente a defesa da sociedade.

Assim, consideram-se também as prioridades da agenda de segurança e de onde partem essas prioridades (do campo político, do campo social, etc.), quais argumentos foram apresentados para isso, que decisões foram tomadas (quais políticas envolvidas).

Segundo a UNODC (2012), o COT envolve de maneira global todas as ações criminosas motivadas pelo lucro, de caráter internacional, onde mais de um país esteja envolvido. As atividades criminosas que podem ser caracterizadas pelo COT, incluem o tráfico de drogas, tráfico de pessoas, tráfico de armas, contrabando, cibercrime, entre outros. Ameaça à paz e a segurança humana, leva à violação dos direitos humanos e prejudica o desenvolvimento econômico, social, cultural, político e civil das sociedades em todo o mundo. A quantia de dinheiro movimentada pelo 
COT pode comprometer economias legitimas impactando direto na governabilidade, por meio da corrupção e outras ilicitudes.

A política é ação na sua essência, e assim, também é a Defesa, porém, ambas se apresentam de diferentes formas a sociedade humana. Assim, o princípio da securitização parte da compreensão de que existem embates, discussões, interesses, e outros antagonismos que de algum modo aproximam e/ou repelem lados, conforme aponta Graciela Pagliari em sua tese.

A securitização se opõe à politização no sentido que, no nível internacional, securitizar significa apresentar um assunto cujo tratamento deva ser prioritário, mas, diferentemente da política, não pode ser aberto à discussão e às barganhas normais deste jogo. A segurança internacional seria, em essência, com as coletividades humanas relacionam-se umas com as outras em termos de ameaças e vulnerabilidades, em função disso, deveria ser estudada em um contexto mais amplo eis que objetos isolados apresentam um interesse menor (PAGLIARI, 2009, p. 37).

Ameaças como o COT e os crimes transnacionais são elementos que preocupam a segurança pública, e estão presentes e atuantes em todos os Estados e democracias da América do Sul, desde as mais solidas até as mais débeis. Cañas (2017) elenca que a consolidação da democracia é um tema pendente em vários países da região, mas se apresenta como uma zona de paz, por mais que tenha ocorrido casos de crises igual a protagonizada entre Venezuela e Colômbia em 2008. Para o autor:

De hecho, el contexto regional ha sido profusamente caracterizado com una Zona de Paz, tanto desde el mundo académico como desde el contexto de la política multilateral. Pero es una Zona de Paz Violenta, atendido el dinamismo que expresa el COT. O sea, es una región pacífica desde el punto de vista interestatal, pero muy conflictiva considerando las índices de la seguridad pública y ciudadana (CAÑAS, 2017: p. 6).

Os crimes transnacionais são motivados pelo enriquecimento econômico irrestrito, associado a mercados ilegais formados, principalmente, pelo narcotráfico; roubo; contrabando; e tráfico de pessoas, de órgãos e de armas. Observa-se uma estreita relação entre o narcotráfico, tráfico de armas e tráfico de pessoas, características de atividades constantes nas fronteiras, em que se autofinanciam, gerando, consequentemente, uma violência urbana (BUZAN, 2012).

Essas ameaças internas, afrontam a soberania do Estado e a sua sobrevivência, então é importante analisar estas questões como problemas estruturais que abalam a ordem política, e isso altera o modo de ver e abordar esses problemas, e consequentemente, combatê-los, portanto, torna-se dentro da agenda de segurança, de algo prioritário.

Essas questões com potencial de destruição devem ser tratadas, portanto, antes de quaisquer outras, porque, caso contrário, o Estado deixará de existir como unidade soberana e todas as demais questões tornar-se-ão irrelevantes. (SAINTPIERRE, 2007)

Partindo deste pressuposto, a securitização permeia no processo por onde um determinado componente é projetado como uma ameaça constante e apresentado como questão de segurança. Dessa forma, percebe-se que "se, por meio de um argumento sobre a prioridade e 
a urgência de uma ameaça existencial, o ator securitizante conseguiu se libertar dos processos ou regras aos quais ele deveria estar vinculado, testemunha-se um caso clássico de securitização" (BUZAN et al., 1998, p. 25).

Percebe-se que a maioria das políticas públicas sul-americanas desenvolvidas para as fronteiras e para o combate ao COT tendem a seguir neste caminho, a securitização do crime organizado, pois conforme nota-se o COT já alcançou o nível de ameaça existencial aos Estados democráticos e a paz social na América do Sul, e por isso se faz necessário medidas extremas de contenção (CEPIK, 2010).

As ações de cooperação entre os países no combate as drogas ou ações pontuais de apreensão e destruição de cultivo de drogas, não são suficientes para estancar o COT visto a complexidade em rede que envolve setores públicos e privados aos mercados ilícitos transnacionais de tráfico de drogas, de armas, de contrabando e tantos outros, cujas cadeias produtiva, logística e financeira existirão enquanto houver oportunidades de mercado para tanto (MEDEIROS, 2018).

Por isso Almeida (2017) elenca que as ações de cooperação deveriam se dedicar à construção de estratégias políticas nas áreas de segurança pública e defesa, destinadas a abalar as estruturas dos mercados ilícitos transnacionais, explorados pelo crime organizado, criando controles voltados ao caráter econômico de tais mercados, com foco na demanda e no consumo.

Assim, de acordo com Buzan (2012) é fundamental desenvolver ação integrada em nível internacional, para identificar, investigar e processar as pessoas e grupos por trás dos crimes. 0 uso de tecnologia e inteligência, necessitam de desenvolvimento através de treinamento de grupos especializados de combate e prevenção, para que se possa ter a aplicação de leis específicas com foco no aparato de unidades de combate equipadas com tecnologias de ponta.

\section{CONSIDERAÇÕES FINAIS}

A busca dos conhecimentos a respeito da securitização diante de novas ameaças conduziu para a verificação do conceito de ameaça no âmbito das políticas internacionais, especialmente na América do Sul, onde há extensas fronteiras secas entre países, que facilitam o desenvolvimento do Crime Organizado Transnacional (COT), pois existem diferentes elementos que contribuem para a proliferação do crime.

As ameaças se constituem na ocorrência de narcotráfico, no tráfico de armas, contrabando, violência urbana, tráfico de pessoas, exploração do trabalho infantil, degradação ambiental e outras atividades que colocam em risco a segurança e a integridade das nações da América do Sul. 
Os interesses divergentes entre as nações, a diversidade cultural e estrutural conduzem os países subdesenvolvidos e enfrentarem problemas que vão além de suas fronteiras e acabam por sofrer a intervenção dos Estados Unidos, que arrogam para si o dever de proteger os interesses democráticos no Continente Americano. Como nem sempre isto é aceito com facilidade, surgem guerrilhas, revoltas, problemas sociais causados pelas sanções econômicas impostas pela intervenção norte-americana. Neste aspecto, a securitização deve decorrer do fortalecimento das instituições regionais formadas pela união dos países da América do Sul tais como: Mercado Comum do Sul - MERCOSUL, Associação Latino-Americana de Integração-ALADI, Comissão Econômica para a América Latina-CEPAL, Associação Latino-Americana de Livre ComércioALALC, instituições estas, voltadas para a organização e o fortalecimento da economia e desenvolvimento dos países. Além da organização econômica, o surgimento da UNASUL veio contribuir para o fortalecimento da cultura e a unificação dos interesses sociais entre os países.

No entanto, as constantes intervenções da América do Norte, especialmente dos Estados Unidos, geram uma condição de interdependência que coloca em risco a autonomia dos países latino-americanos. No entanto, no início de 2019, o Brasil abandonou a UNASUL e seus princípios em busca de estabelecer valores neoliberais, o que contribui para que o COT dê um passo a frente e fortaleça as ameaças que permeiam os conflitos da América do Sul. Neste aspecto, o Estado brasileiro optou no início de 2019, por participar de um processo de securitização amparado na militarização e o combate às ameaças deve ser realizado pela força militar, este processo de combate ao tráfico de drogas, ao contrabando e outras ameaças é dificultado pela extensão de fronteiras do Brasil, pois dentre os países sul-americanos somente o Chile e Equador não possuem fronteiras com o Brasil. Além disso, a modernização tecnológica proporcionadas pela agilidade nas comunicações e transportes contribuem para que o COT seja ameaça em todos os continentes.

Diante de tudo o que foi estudado percebe-se que a securitização do crime organizado transnacional na América do Sul é um aspecto das relações internacionais que necessita ser amplamente estudado e esclarecido, pois somente a ampla compreensão deste fenômeno pode contribuir para que sejam adotadas medidas de combate mais efetivas e adequadas à realidade do continente americano.

Recebido em: 6 de junho doe 2019

Aprovado em: 24 de julho de 2019

\section{REFERÊNCIAS}

ALMEIDA, Letícia N. Subsistema fronteiriços do Brasil: mercados ilegais e violência. Rio de Janeiro: Gramma, 2017. 
BUZAN, Barry: WAEVER, Ole; WILDE, Jaap de. Security: a new framework for analysis.Boulder: Lyne Rienner Publishers, 1998.

BUZAN, Barry. A evolução dos estudos de segurança internacional / Barry Buzan, Lene Hansen; tradução Flávio Lira. São Paulo: Ed. Unesp, 2012.

CAÑAS, Sergio Salinas, Riquelme Rivera, Jorge. Democracia, integración y seguridad en América Latina: el Crimen Organizado Transnacional (cot) como desafío. Revista Enfoques: Ciencia Política y Administración Pública 2017, XV (Julio-Diciembre). Disponível em:<http://redalyc.org/articulo.oa?id=96055458007> ISSN 0718-0241. Acesso em: 06 dez. 2018.

Centro de Estudios Estratégicos de la Defensa (CEED) Unasur y la cooperación en la lucha contra el crimen organizado transnacional y los delitos transfronterizos. 2012. Disponível em: <http://www.ceedcds.org.ar/Espanol/09-Downloads/CRIMEN_ORGANIZADO. pdf>. Acesso em: 06 dez. 2018.

CEPIK, Marco. Segurança Internacional: Práticas, tendências e conceitos. São Paulo: Hucitec, 2010.

FRAMENTO, Rodrigo de Souza; FERREIRA, Marcos Alan S. V. Unasul e a promoção da paz social: A institucionalização do Conselho de Segurança Cidadã, Justiça e Ações contra o Crime Organizado Transnacional. RICRI vol. 5, n. 10, pp. 134-168. 2017.

FERREIRA, Marcos Alan S. V. Estudos Críticos da Paz e Crime Organizado Transnacional. 2017. Revista Crítica de Ciências Sociais, 113.

FERREIRA, Oliveiros S. Clausewitz e a política. In: Lua Nova: Revista de Cultura e Política. n 34 (pp. 27-35). 1994.

FREITAS, Raquel C. A Unasul e o papel da Democracia nos Países da América do Sul. Revista Eletrônica Direito e Política, Programa de Pós-Graduação Stricto Sensu em Ciência Jurídica da UNIVALI, Itajaí, v. 11, n.1 1ำ quadrimestre de 2016.

LYRA, Mariana P. O. de. O Processo de Dessecuritização do Narcotráfico na UNASUL. Dissertação (Mestrado em Relações Internacionais), Universidade Estadual da Paraíba, João Pessoa. 2014.

MEDEIROS, Juliana L. de. Cooperação Bilateral no Combate à Criminalidade Organizada Transnacional: uma análise das ações brasileiro-paraguaias nas regiões de fronteira. João Pessoa, Dissertação (Mestrado) UFPB/CCSA. 2018.

NAÇÕES UNIDAS, Assembléia Geral (2004) Relatório do grupo de alto nível sobre ameaças, desafios e mudanças. Um mundo mais seguro: a responsabilidade que compartilhamos. Disponível em www.world-governance.org/IMG/pdf_complet_ES.pd

PAGLIARI, Graciela de C. Segurança regional e politica externa brasileira: as relações entre Brasil e América do Sul, 1990-2006. Brasília, Tese (Doutorado em Relações Internacionais), Universidade de Brasília - UnB. 2009.

PEREIRA, Paulo José dos R. Securitização do Crime Organizado Transnacional nos Estados Unidos na década de 1990. Campinas, SP, Tese (Doutorado em Ciência Política), Universidade Estadual de Campinas (UNICAMP) 2011.

SAINT-PIERRE. Héctor Luis. As “Novas Ameaças” às Democracias Latino americanas: uma abordagem Teórico Conceitual. 2007.2 Disponível em: 
https://www.academia.edu/8476365/AS_NOVAS_AMEA\%C3\%87AS_\%C3\%80

S_DEMOCRACIAS_LATINOAMERICAN̄AS_UMA_ABORDAGEM_TËORICO_CONCEITUAL.

União de Nações Sul-Americanas (UNASUL) Tratado constitutivo da Unasul.2008. Disponível:<http://www.itamaraty.gov.br/images/ed_integracao/docs_UNASUL/TRAT_CONST_P ORT.pdf>. Acesso em: 08 dez. 2018.

UNODC - United Nations Office on Drugs and Crime (2012) Estimating Illicit Financial Flows Resulting from Drug Trafficking and other Transnational Organized Crimes. Vienna: UNODC.

WOLFERS, Arnold."National Security" as an Ambiguous Symbol. Political Science Quarterly, v. 67, n. 4, p.481-502, dez. 1952. 